\title{
ARGUMENTAÇÃO JURÍDICA PARA SUPRESSÃO DE ÁRVORES NATIVAS NAS FAIXAS DE DOMÍNIO
}

\author{
Dayane Thomazi Maia ${ }^{1}$
}

Barbara Stolte Bezerra ${ }^{2}$

\begin{abstract}
RESUMO
Faixa de domínio é o conjunto de áreas declaradas de utilidade pública, desapropriadas por decreto ou apossamento administrativo e necessárias para implantação das obras de estrada ou rodovia e seus dispositivos operacionais. A ausência de arborização na faixa de domínio das rodovias está diretamente relacionada à segurança viária, pois os motoristas que trafegam pelas rodovias utilizam estas áreas como escape em caso de emergência ou acidentes com saída de pista. O risco e a severidade de acidentes são agravados pela existência de vegetação arbórea numa faixa de domínio, podendo levar o veículo a chocar-se com essa vegetação. Este trabalho teve por escopo fazer a análise de algumas questões relativas ao tema da segurança viária, através da análise das legislações que envolvem a manutenção viária e legislação ambiental pertinente ao tema. A primeira questão levanta-se no âmbito das leis ambientais e as possíveis consequências do corte de árvores nativas presentes nas faixas de domínio. A segunda questão diz respeito à aparente predominância do direito ambiental sobre o direito de proteção à vida humana, tanto no âmbito dos direitos humanos quanto nas garantias fundamentais previstas na Constituição Federal. Portanto, a discussão deste trabalho está no fato que a supressão de árvores nativas ou não em vias com tráfego de alta velocidade é indispensável para a segurança viária e, por isso, não deve ser exigida a compensação ambiental.
\end{abstract}

Palavras-chave: supressão de árvores nativas; compensação ambiental; segurança viária; legislação ambiental.

\section{LEGAL ARGUMENTS FOR ELIMINATION OF NATIVE TREES IN THE FIELD OF BANDS}

\begin{abstract}
Of-way is the set of declared public utility areas expropriated by decree or administrative possession necessary for implementation of road works or highway and its operating devices. The absence of trees ranging from the field of roads is directly related to road safety, the drivers who travel the highways can use these areas as escape in case of an emergency or run-off accident. The risk and the severity of accidents are aggravated by the presence of arboreal vegetation at road side and may
\end{abstract}

1 Bacharel de Direito, Instituto de Ensino Superior de Bauru - IESB Bauru, Departamento de Direito, dtm@yahoo.com.br

${ }^{2}$ Dr. Engenharia de Transportes, UNESP - Univ. Estadual Paulista. barbarabezerra@feb.unesp.br 
Revista Nacional de

Gerenciamento de Cidades

lead vehicle to collide into this vegetation. This work has the scope to examine the laws involving road maintenance and environmental legislation relevant to the topic. The first issue arises under environmental laws and the possible consequences of cutting native trees present at the road side. The second issue concerns the apparent predominance of environmental law on the right of protection of human life, both in the context of human rights and the fundamental guarantees provided for in the Federal Constitution. Therefore, the discussion of this work lies in the fact that the suppression of native or non native trees at road side of high speed roads is essential for road safety and therefore should not require environmental compensation.

Keywords: suppression of native trees; environmental compensation; road safety; environmental legislation.

\title{
ARGUMENTOS LEGALES PARA ELIMINACIÓN DE ÁRBOLES NATIVOS EN EL ÁMBITO DE BANDAS
}

\begin{abstract}
RESUMEN
De paso es el conjunto de las zonas declaradas de utilidad pública, expropiadas por decreto o apossession administrativa y necesaria para la ejecución de obras en la carretera o autopista y sus dispositivos de accionamiento. La ausencia de árboles que van desde el campo de las carreteras está directamente relacionada con la seguridad vial, ya que los conductores que viajan las carreteras utilizan estas zonas como de escape en caso de emergencia o accidente con la escorrentía. El riesgo y la gravedad de los accidentes se ven agravados por la presencia de vegetación árbol en la vía y pueden conducir vehículo para toparse con esta vegetación. Este trabajo fue su alcance al examen de ciertas cuestiones relacionadas con el tema de la seguridad vial a través del análisis de las leyes que implican el mantenimiento de carreteras y la legislación ambiental pertinente al tema. La primera cuestión se deriva de las leyes ambientales y las posibles consecuencias de la tala de árboles nativos presentes en los rangos de área. La segunda cuestión se refiere al aparente predominio del derecho ambiental en el derecho a la protección de la vida humana, tanto en el contexto de los derechos humanos y las garantías fundamentales previstas en la Constitución Federal. Por lo tanto, la discusión de este trabajo radica en el hecho de que la supresión de árboles nativos o no en la pista con el tráfico de alta velocidad es esencial para la seguridad vial y, por tanto, no se debe exigir compensación ambiental.
\end{abstract}

Palabras clave: supresión de árboles nativos; compensación ambiental; seguridad vial; legislación ambiental.

\section{INTRODUÇÃO}

O fluxo de veículos que trafegam por rodovias vem sofrendo significativo aumento em razão do trânsito intermunicipal de pessoas e cargas, e que tem como 
Revista Nacional de

Gerenciamento de Cidades

consequência o aumento do número de acidentes, principalmente aqueles denominados de acidentes de saída de pista. Estes, segundo definição da AASHTO (2013), ocorrem quando o veículo sai da faixa de rolagem e invade o acostamento, chegando a áreas externas, tornando o veículo passível ao choque com um ou mais objetos fixos, em especial as árvores de grande porte.

É importante ressaltar os "Aspectos Legais" vinculados à implantação de revestimento vegetal, em especial concernente à "Supressão de Vegetação" para a implantação rodoviária nas Faixas de Domínio. Não existe lei que regulamente o plantio de árvores à beira de estradas, mas a Agência Reguladora de Transportes de São Paulo não recomenda, por uma questão de segurança, e também regulamenta em Edital de Licitação, que todas as Concessionárias eliminem em até 24 horas, árvores das Faixas de Domínio que representem perigo ao tráfego (ARTESP, 1997).

Segundo O CTB (Código de Trânsito Brasileiro), o uso das Faixas de Domínio e laterais das Rodovias deve obedecer às condições de segurança do trânsito estabelecidas pelo órgão ou entidade com circunscrição sobre a via. Desta forma, deverá ser feita uma fiscalização rigorosa por parte dos órgãos competentes quanto às vegetações existentes nas faixas de domínio que possam comprometer a segurança nessas vias.

Com a regulamentação das faixas de domínio das Rodovias no Estado de São Paulo, tem-se que o principal objetivo é a segurança do motorista, de seus passageiros e das pessoas que residam nas áreas lindeiras, evitando e prevenindo acidentes. Salienta-se que há dois bens a preservar. De um lado, o bem que se revela no direito à vida humana; de outro, o bem que se perfaz no direito ao meio ambiente. $O$ direito à vida é tutelado constitucionalmente na qualidade de garantia fundamental, portanto, com tutela superior a demais direitos. Já o direito ambiental, embora tutelado constitucionalmente, não participa do rol de garantias fundamentais, logo é inferior ao direito à vida. Análises doutrinárias demonstram que o bem vida humana é o objetivo maior de qualquer ordem jurídica e conclui que o direito ao 


\section{Revista Nacional de}

Gerenciamento de Cidades

meio ambiente é apenas um complemento daquele. $O$ meio ambiente deve ser preservado até o limite onde não esteja prejudicando ou diminuindo a preservação da vida humana.

Este trabalho teve a intenção de iniciar a discussão jurídica para propor o fim da flagrante inconsistência legal que é a manutenção de espécies arbóreas nativas nas faixas livres de obstáculos nas rodovias de alta velocidade, desconsiderando qualquer compensação ambiental, o que vem inviabilizando muitas vezes supressão de tais espécies. Repita-se que tais faixas têm por objetivo a proteção à vida humana e são previstas nos manuais de segurança rodoviária internacionais. A simples remoção de árvores (nativas ou não) das laterais das rodovias, por si só, seria uma medida eficaz para a redução de mortes desnecessárias. A Organização das Nações Unidas sugere que a atual década seja voltada para o trânsito seguro, momento ideal, portanto, para trazer à tona esta discussão no país.

\section{PROCEDIMENTOS METODOLÓGICOS}

Seguindo os procedimentos apresentados nos trabalhos estudados, a pesquisa sobre o assunto foi desenvolvida contendo inicialmente os seguintes itens:

\section{Pesquisa Bibliográfica}

Foi realizada pesquisa bibliográfica referente: a estrutura das rodovias do Estado de São Paulo e dimensões apropriadas para cada trecho e seus componentes; levantamento dos custos relativos aos danos causados em caso de acidente, inclusive ao meio ambiente, assim como sua relação direta com o PIB do país; avaliação de risco da lateral da via, com pesquisa sobre a atual margem de acidentalidade no trânsito com saída de pista e colisão com árvores, buscando ações para a redução da acidentalidade viária; consulta jurídica sobre: legislação, doutrina, jurisprudência, direito comparado, entre outras normas que regem o tema 


\section{Revista Nacional de}

em estudo, em especial o Código de Trânsito Brasileiro, o Código Civil, o Código Florestal, Manuais do DER - SP e DNIT, assim como Leis Especiais, Decretos, Portarias, Resoluções, Estatutos, entre outros.

\section{Visitas Técnicas para resolução do problema}

Para as orientações e diretrizes quanto à supressão de árvores nas rodovias do Estado de São Paulo, assim como a análise das leis que são utilizadas para a manutenção das faixas de domínio das rodovias, foram realizadas visitas técnicas com aplicação de questionários nos seguintes setores: Secretarias de Trânsito e Departamento de Estrada e Rodagem do Estado de São Paulo, responsáveis por algumas rodovias e municípios da região de Bauru; Concessionárias com circunscrição sobre algumas vias da Região de Bauru para análise de contratos e Termos de Uso das vias; Secretarias de Meio Ambiente responsáveis por alguns municípios da região de Bauru e à CETESB.

\section{ARCABOUÇO TEÓRICO E JURÍDICO}

Esta seção traz a revisão bibliográfica e o arcabouço teórico e jurídico para o embasamento das discussões do tema do artigo. Primeiro é feito uma descrição da estrutura rodoviária e dos custos dos acidentes de trânsito no país e meios de prevenção de acidentes. Depois são apresentadas as legislações pertinentes ao tema.

\subsection{Estrutura Rodoviária}

As faixas de tráfego ou faixas de rolamento são os comprimentos unitários destinados à transição dos veículos. A largura dessas faixas é obtida adicionando-se a largura do veículo de projeto à largura de uma determinada medida de segurança, sendo função da velocidade de projeto e do nível de conforto de viagem que se deseja proporcionar. A pista de rolamento é o espaço correspondente ao conjunto 
Revista Nacional de

Gerenciamento de Cidades

das faixas de tráfego contíguas. O acostamento ou faixa lateral é o espaço adjacente às faixas de tráfego que é destinado à parada emergencial de veículos, não sendo em geral dimensionado para suportar o trânsito de veículos (que pode ocorrer em caráter esporádico). Quando pavimentados, os acostamentos contribuem para conter e suportar a estrutura do pavimento da pista, as larguras dos acostamentos dependem da classe de projeto da rodovia e do tipo de terreno atravessado (Macedo, 2010).

As faixas de domínio correspondem às larguras desapropriadas para a construção da estrada, possuindo, normalmente, $50 \mathrm{~m}$ de largura, podendo eventualmente apresentar 30, 80 ou $100 \mathrm{~m}$, de acordo com a categoria da estrada (Macedo, 2010). Há necessidade que sejam estipuladas larguras nos projetos para as faixas de domínio que estão sujeitas a pressões de natureza sócio-econômicas das pessoas que atuam nas áreas lindeiras à rodovia, principalmente nas áreas próximas aos centros urbanos. Assim, os critérios para definição das larguras de faixas de domínio não são rígidos, e devem considerar os referidos fatores ambientais, conforme atribuições do DNIT estabelecidas na Lei $n^{\circ} 10.233$, de 05/06/2001. A via, portanto, tem sua largura total estimada na soma das faixas de tráfego com as faixas de domínio laterais.

A zona livre de obstáculo na lateral das rodovias é definida como a área de borda lateral da via, começando na borda da pista de rolamento, disponível para uso seguro pelos veículos desgovernados. A largura desejável da zona livre, do ponto de vista da segurança da lateral de via, é tão ampla quanto possível no que se refere ao custo-eficácia, sendo que os valores do projeto da zona livre são determinados e dependem das velocidades de tráfego e da geometria da lateral da via (SHA, 2006; AASHTO, 2006). Em 1974, a AASHTO conceituou que para haver uma segurança adequada na lateral de uma via, deve ser mantido um espaço de, no mínimo, 9 metros de largura, principalmente nas rodovias de alta velocidade, permitindo dessa forma, que cerca de $80 \%$ dos veículos que saiam da pista recuperem o controle. Já em 1977 a AASHTO modificou o conceito de zona livre com largura fixa de 9 metros, 
Revista Nacional de

Gerenciamento de Cidades

passando essa largura a ser calculada em função da velocidade, da declividade lateral e do Volume Diário Médio (VDM) de veículos que passam nas rodovias, procedimento que é utilizado atualmente, no entanto a largura mínima da zona livre ainda é estabelecida em 9 metros (AASHTO, 2006).

\subsection{Custos dos Acidentes de Trânsito}

Segundo a OMS (2005), os acidentes de trânsito são a principal causa de morte violenta entre os indivíduos de 10 a 24 anos. Nos países desenvolvidos, os acidentes de trânsito representam quase $10 \%$ dentre todas as causas de morte prematura entre pessoas na faixa etária de 5 a 44 anos. Pelo menos 1,2 milhões de pessoas perdem a vida todos os anos nas rodovias e estradas mundiais. Os acidentes e respectivas violências representam importante problema de saúde pública, que atinge países do mundo inteiro. O Brasil, nas últimas décadas, foi, aos poucos, colocando-se entre os campeões mundiais de acidentes de trânsito.

Segundo dados do DNIT (2004), os acidentes de trânsito representam, anualmente, de 1 a $3 \%$ do produto nacional bruto de um país. No Brasil, estima-se gastos em torno de $1,5 \%$ a $2,0 \%$ do PIB com acidentes de trânsito. É importante ressaltar que, ainda segundo o DNIT (2004), na distribuição por "Tipo de Acidente nas Rodovias", o choque com objeto fixo corresponde a $6,7 \%$ dos acidentes e os Acidentes com Saída de Pista correspondem a $27,5 \%$ dos acidentes. São estes que estão intrinsecamente relacionados com o choque em árvores nas laterais da via. Segundo dados da ARTESP (2010), dos acidentes fatais com saída de pista, 3,1\% ocorreram devido ao choque com árvores, sendo extremamente importante o estudo da segurança do entorno da via e da manutenção dessa vegetação. As colisões de veículos simples com árvores representam anualmente quase $25 \%$ de todas as colisões fatais com obstáculos fixos e resultam na morte de aproximadamente 3.000 pessoas a cada ano nos Estados Unidos (AASHTO, 2006). 
Revista Nacional de

Gerenciamento de Cidades

\subsubsection{Tipos de Danos}

Em pesquisa recente, apresentada no livro Segurança Viária (Ferraz et al. 2012), os custos com acidentes de trânsito podem ser divididos em três classes de danos: o dano econômico, o dano humano e social e o dano ambiental.

\section{Dano econômico}

Segundo WHO (2004) apud Ferraz et al. (2012), o custo dos acidentes de trânsito no ano de 2002, considerando em conjunto todos os países do mundo, foi estimado em US\$ 518 bilhões. Considerando o aumento do número de acidentes e a inflação da moeda americana no período 2002 - 2012, estima-se que esse número seja, atualmente, cerca de US\$ 1 trilhão. A Tabela 1 apresenta os valores atualizados relativos ao ano de 2012 dos custos de acidentes apresentados em IPEA (2003) e IPEA (2006), tomando-se como base a variação do IPCA do IBGE: de $67,42 \%$ no período de 2003 - 2011 e de $41,72 \%$ no período de $2006-2011$.

Tabela 1: Custos dos acidentes de trânsito IPEA (2003 e 2006) atualizados para 2012

\begin{tabular}{cccc}
\hline Discriminação & Rodovias & Cidades & País \\
\hline Acidente sem vítima $(\mathrm{R} \$)$ & $23.866,00$ & $5.461,00$ & - \\
Acidente com vítimas não fatais $(\mathrm{R} \$)$ & $121.925,00$ & $29.231,00$ & - \\
Acidente com vítimas fatais $(\mathrm{R} \$)$ & $592.873,00$ & $241.320,00$ & - \\
Todos os tipos de acidentes $(\mathrm{R} \$)$ & $83.445,00$ & $14.704,00$ & - \\
Total anual (bilhões de $\mathrm{R} \$ / \mathrm{ano})$ & 39,50 & 12,65 & 52,15 \\
\hline
\end{tabular}

Fonte: Segurança Viária (Ferraz et al. 2012).

Conforme é possível observar na Tabela 1, o valor do custo total dos acidentes para o ano de 2012, estimado em 52,15 bilhões de reais, correspondente a aproximadamente $1,21 \%$ do PIB brasileiro previsto de 4,3 trilhões de reais (valor 


\section{Revista Nacional de}

Gerenciamento de Cidades

que se situa entre 1,0 e 1,5\%, que são os percentuais adotados por WHO (2004) na estimativa do custo total dos acidentes nos países com nível de desenvolvimento baixo e médio, respectivamente).

\section{Dano humano e social}

Além dos custos econômicos com acidentes, é importante ressaltar os custos relativos ao ser humano, como o sofrimento físico e psicológico das vítimas, o sofrimento psicológico de seus familiares, danos e doenças psicológicas da vítima e dos familiares, desestruturação econômica de familiares, distanciamento de entes queridos em razão do tratamento hospitalar e de reabilitação. $O$ trauma psicológico da vítima e de seus familiares é muito grande e perdura durante um longo tempo com tratamentos desgastantes que alteram a rotina e desestabilizam o núcleo familiar.

\section{Dano ambiental}

Para acidentes de trânsito decorrentes de choque com árvores nas faixas de domínio, além dos demais danos acima listados, há também o dano ambiental, dano este difícil de mensurar, mas que traz grande prejuízo ao meio ambiente. São decorrentes do derramamento de combustível ou outros tipos de produtos transportados pelos veículos que, ao entrarem em contato com o solo, podem atingir lençóis freáticos, provocando degradação ambiental através de contaminação. Também no caso de APP (Área de Preservação Permanente) ou APA (Área de Preservação Ambiental) à margem das pistas, os escoamentos de resíduos nas águas podem provocar desequilíbrio na flora, na fauna e até mesmo no clima.

Também é importante ressaltar que quando ocorre o choque de um veículo automotor com uma árvore nativa numa faixa de domínio, além dos danos causados ao veículo e à vítima, o choque também comprometerá tal vegetação, podendo 
Revista Nacional de

Gerenciamento de Cidades

inclusive, quando a árvore que se situa na faixa de domínio for de grande porte, provocar sua queda na via e comprometer ainda mais o tráfego e a segurança de outros motoristas. O risco de combustão é outro grave problema relacionado ao choque de veículo com árvore numa faixa de domínio. Para o meio ambiente, vez que as faixas de domínio são normalmente compostas por vegetações que podem propagar o fogo, o comprometimento de tal acidente pode trazer danos efetivos à flora e fauna.

\subsection{Prevenção}

O Quadro 1 apresenta uma versão adaptada da matriz de Haddon, listando as ações durante o Pré-Acidente, o Acidente e o Pós-Acidente. Notar que das formas de prevenção de acidentes, definidas nesta tabela em seu primeiro tópico, o de "Pré-Acidente", na parte que se refere ao meio ambiente, são citadas formas para prevenir acidentes, como: "faixa lateral com superfície regular, pequena declividade e sem obstáculos; Inexistência de elementos próximos que prejudiquem a visibilidade ou desviem a atenção". No segundo tópico da tabela, na sessão intitulada "Acidente", que se refere à "Prevenção de traumatismos durante o acidente", ressalta-se o tópico: "faixa lateral com superfície regular, baixa declividade e sem obstáculos", ou seja, uma espécie arbórea na faixa de domínio das rodovias servirá como obstáculo em caso de emergências nas vias, podendo levar a colisão do veículo que escapar da faixa de rolamento. Ratifica-se, portanto, que a prevenção é a melhor opção para reduzir danos causados ao meio ambiente.

Outro ponto importante é que essa mesma espécie arbórea poderá comprometer a visibilidade dos motoristas que trafegam nas vias ao fazerem curvas ou, particularmente no caso de rodovias de pista simples, a folhagem das copas pode ocultar veículos durante manobras de ultrapassagem, especialmente em decorrência do alto porte da vegetação, além da possibilidade da queda dessa vegetação (no caso de árvores de grande porte), podendo atingir a pista e interferir no trânsito e na segurança dos motoristas. 
Revista Nacional de

Gerenciamento de Cidades

O risco de incêndios é um problema pertinente à presença de árvores nas faixas de domínio, pois o choque de um veículo com uma árvore poderá aumentar as chances de combustão, principalmente em dias mais quentes, especialmente devido ao risco de vazamento de combustível no solo, ou até mesmo no caso de choque de veículos que transportam produtos inflamáveis. Se ocorrer o choque de veículo automotor com uma árvore e houver combustão, há grande chance do fogo se propagar e atingir áreas de reservas florestais, destruindo, em vez de uma, várias árvores e podendo causar um dano incomensurável ao meio ambiente.

\section{Quadro 1: Versão adaptada da matriz de Haddon}

\begin{tabular}{|c|c|c|}
\hline PERIODO & EIEMENTO & EXEMPLOS DE ACOOES \\
\hline \multirow{3}{*}{$\begin{array}{c}\text { PRE- } \\
\text { ACIDENTE } \\
\text { Prevencaio do } \\
\text { acidente }\end{array}$} & Humane & 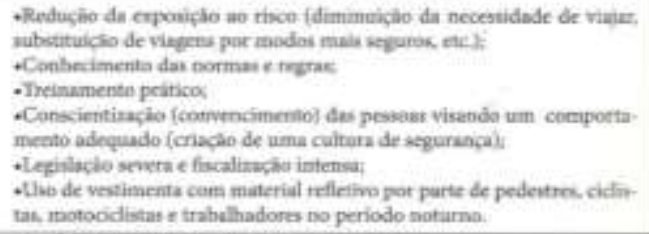 \\
\hline & Veiculo & 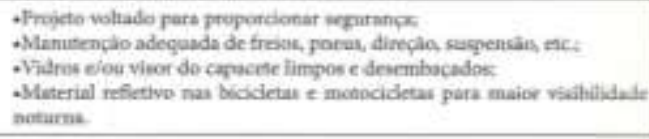 \\
\hline & $\begin{array}{l}\text { Viaimeis } \\
\text { ambiente }\end{array}$ & 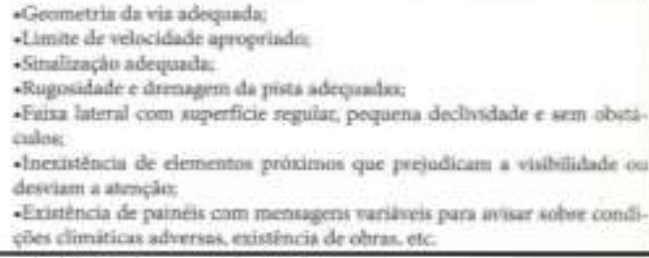 \\
\hline \multirow{3}{*}{$\begin{array}{l}\text { ACIDENTE } \\
\text { Prevenção de } \\
\text { traumatismos } \\
\text { duranteo } \\
\text { acideate }\end{array}$} & Humano & 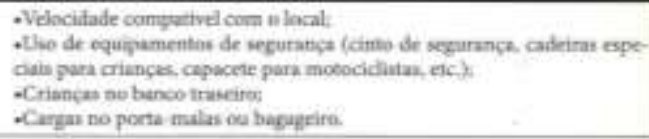 \\
\hline & Veiculo & 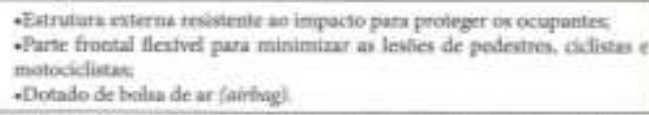 \\
\hline & $\begin{array}{l}\text { Via/meio } \\
\text { ambiente }\end{array}$ & 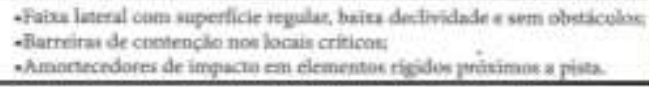 \\
\hline \multirow{3}{*}{$\begin{array}{c}\text { PÓs: } \\
\text { ACIDENTE } \\
\text { Conservacão } \\
\text { da vida }\end{array}$} & Hanases & 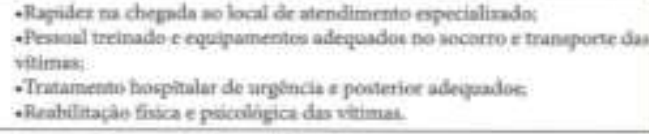 \\
\hline & Veicule & 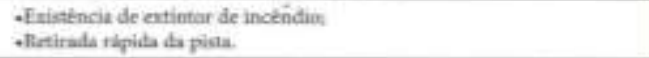 \\
\hline & $\begin{array}{l}\text { Via/meio } \\
\text { smibiente }\end{array}$ & 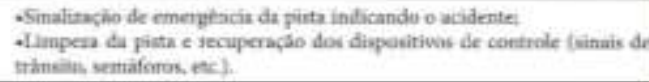 \\
\hline
\end{tabular}

Fonte: Adaptado de Ferraz et al. (2012). 
Revista Nacional de

Gerenciamento de Cidades

Nesta mesma linha, também é importante ressaltar que no caso de queimadas em florestas próximas as rodovias, se a faixa de domínio não estiver livre de exemplares arbóreos, o fogo poderá chegar a essas árvores que se situam na faixa de domínio e, consequentemente, comprometer a segurança dos motoristas que terão que se desviar da fumaça ou trafegarão com baixa visibilidade.

O DNIT (2005) define prevenções para que as queimadas e os incêndios não comprometam os motoristas que trafegam pelas vias. Entre essas formas de prevenção, estão os aceiros. Estes representam uma forma de técnica destinada a quebrar a continuidade do material combustível, constituindo tal técnica, basicamente, na criação de faixas livres de vegetação, onde o solo fica exposto, seguindo distribuição normativa de acordo com as necessidades de proteção locais. É imprescindível que as faixas de domínio ao longo das estradas sejam mantidas livres de vegetação que propague o fogo, devendo haver uma rígida fiscalização a esse respeito, pois a segurança humana é prioridade.

\subsection{Previsão Legal para a Intervenção na Vegetação das Faixas de Domínio}

A partir das visitas técnicas realizadas no período em estudo, foi possível fazer um levantamento das principais normas aplicadas e executadas para a manutenção das Faixas de Domínio das Rodovias. Dentre as normas que regulamentam a intervenção de espécie arbórea na faixa de domínio estão: O Manual de Vegetação Rodoviária do DNIT (2009), a Lei 12.651/2012 (Novo Código Florestal), a Resolução SMA 81/1998, a Resolução SMA 18/2007 e o CONAMA que serão brevemente especificadas a seguir:

a) Manual de Vegetação Rodoviária do DNIT (2009): o manual orienta que os pedidos de Autorização para Supressão de Vegetação (ASV) devam ser apresentados ao IBAMA, sendo que os requisitos básicos para instrução desse pedido são: apresentação de laudo florestal (levantamento ou cadastro fitofisionômico) sobre a área objeto do pedido e sua localização em base cartográfica oficial, incluindo-se, portanto, as faixas de domínio, com destaque para as APP. 
Revista Nacional de

Gerenciamento de Cidades

Cabe ressaltar que, na elaboração dos projetos e na execução dos serviços, deve ser observado o que estabelecem as Normas DNIT de Especificações de Serviço ES e de Procedimento - PRO.

b) Novo Código Florestal e a Supressão em APP: a supressão dessa vegetação é regulamentada pelo novo Código Florestal (Lei 12.651/2012) constituído pela Lei ${ }^{\circ}$. 4771, de 15/09/65, e alterações posteriores, como a Lei $n^{\circ} .7 .803$ de 18/07/89 e a Lei $\mathrm{n}^{\circ}$. 7.875/89, e também o Decreto $\mathrm{n}^{\circ}$. 6.600, de 21/11/08, que regulamenta a Lei $\mathrm{n}^{\circ}$ 11.428, de 22/12/06, que dispõe sobre o corte e a supressão de vegetação da Mata Atlântica. A supressão de vegetação em Área de Preservação Permanente - APP somente deve ser autorizada em caso de utilidade pública ou de interesse social (construção rodoviária, por exemplo), devidamente caracterizado e motivado em procedimento administrativo próprio, quando inexistir alternativa técnica e locacional ao empreendimento proposto, como determinado no artigo $4^{\circ}$ do Código Florestal, com as alterações introduzidas através da Medida Provisória n. 2166/67. Os órgãos ambientais podem autorizar a supressão eventual e de baixo impacto ambiental, assim definido em regulamento, da vegetação em Área de Preservação Permanente, conforme $\S 3^{\circ}$ do artigo $4^{\circ}$ do Código Florestal.

c) Resolução SMA 81/1998 - Hipóteses de Intervenção em Vegetação Arbórea sem Licenciamento Ambiental: a Resolução dispõe sobre o licenciamento ambiental de intervenções destinadas à conservação e melhorias de rodovias e sobre o atendimento de emergências decorrentes do transporte de produtos perigosos em rodovias, tendo em vista o disposto no art. $2^{\circ}$, $\S 2^{\circ}$, da Resolução n. ${ }^{\circ} 237$, de 19 de dezembro de 1997, do Conselho Nacional do Meio Ambiente. No artigo $1^{\circ}$ da referida Resolução em seus incisos estão definidas inúmeras hipóteses que não dependem de licenciamento ambiental nos limites da faixa de domínio de rodovias que se encontrem em operação, entre elas estão a supressão de vegetação nativa secundária, em estágio inicial de regeneração; a supressão de exemplares arbóreos exóticos; a poda de árvores nativas, cujos galhos invadam o acostamento ou a faixa de rolamento, encubram a sinalização ou em situação de risco iminente à segurança; e a implantação de uma faixa adicional contígua às faixas existentes, entendida como a terceira faixa, sem supressão de vegetação nativa arbórea, primária ou 
Revista Nacional de

Gerenciamento de Cidades

secundária, nos estágios médio e avançados de regeneração, e sem relocação de população.

d) Resolução SMA 18/2007 - Procedimentos para a autorização de supressão de exemplares arbóreos nativos isolados: essa resolução define exemplares arbóreos nativos isolados aqueles situados fora de fisionomias vegetais nativas sejam florestais ou savânicas, cujas copas ou partes aéreas não estejam em contato entre si, destacando-se da paisagem como indivíduos isolados. Em seu artigo $1^{\circ}$ define que a autorização para supressão de exemplares arbóreos nativos isolados, vivos ou mortos, situados fora de Áreas de Preservação Permanente e Reserva Legal, assim definidas pelos artigos $2^{\circ}$ e 16 do Código Florestal ou fora de Parques, Reservas e Estações Ecológicas assim definidas por ato do Poder Público, quando indispensável para o desenvolvimento de atividades, obras ou empreendimentos, será emitida pelo Departamento Estadual de Proteção dos Recursos Naturais DEPRN, por intermédio de suas Equipes Técnicas, após a realização de análise técnica e mediante assinatura de Termo de Compromisso de Recuperação Ambiental que contemple plantio compensatório, na proporção prevista no Artigo $8^{\circ}$ desta Resolução.

\subsection{Previsão Doutrinária quanto a Supressão da Vegetação das Faixas de Domínio}

Segundo a teoria defendida por Trindade (1992) o meio ambiente é uma extensão do direito à vida, à saúde, entre outros, então, só há de se falar em direito ambiental se for possível garantir o direito à vida digna, tendo em vista que aquele é complementar a este. Ao tratar da natureza jurídica dos direitos humanos, entre eles o direito ao meio ambiente sustentável, é importante ressaltar o que descreve o art. 225 da Constituição da República Federativa do Brasil: "Todos têm direito ao meio ambiente ecologicamente equilibrado, bem de uso comum do povo e essencial à sadia qualidade de vida, impondo-se ao Poder Público e à coletividade o dever de defendê-lo e preservá-lo para as presentes e futuras gerações." Observando este 
Revista Nacional de

Gerenciamento de Cidades

disposto, nota-se que é realmente sustentável a tese de que o direito ao Meio Ambiente é um direito propriamente humano, sendo um objeto a ser tutelado, ou seja, o valor da natureza está limitado à sua relação com o homem e a sua proteção é justificada pela necessidade de se proteger a vida humana, seja ela presente ou futura.

Trindade (1992) apresenta o primeiro conflito que surge a partir desta percepção do direito ambiental como direito à qualidade de vida, surgindo o enfoque acerca da "vida" que está sendo tutelada. Tendo como objeto de estudo a relação do homem com a natureza, se torna necessário ressaltar a sobreposição do Direito a Vida e a Segurança Humana sobre o Direito ao Meio Ambiente, segundo a Teoria de Trindade, na medida em que novos direitos, como o direito ambiental, vão adquirindo aceitação universal é possível incluí-los no rol dos direitos indisponíveis por meio de sue núcleo. Esses direitos visam ampliar a proteção dos direitos preexistentes (direito à vida e a segurança humana) em vez de limitá-los ou substituí-los. O direito ao meio ambiente reforça outros direitos humanos já existentes, trazendo novas dimensões a estes. Desta forma, pode-se perseguir a proteção ambiental reivindicando-se direitos já existentes, uma vez entendido como direito humano, o direito ao meio ambiente vem enriquecer o corpus dos direitos humanos reconhecidos, e não restringir o uso destes direitos.

O doutrinador Furtado (2003) expõe que em conseqüência ao disposto, a relação do homem com a natureza resulta na criação de uma hierarquia na qual a humanidade detém posição de superioridade, acima e separada dos demais membros da comunidade natural. Os direitos fundamentais à vida, à saúde e a qualidade de vida são fatores determinantes para os objetivos da proteção ambiental. Assim, o meio ambiente deve ser protegido até o limite necessário para a proteção da vida humana. 
Revista Nacional de

Gerenciamento de Cidades

\section{DISCUSSÃO}

A presença de árvores de grande porte próximas à pista, e que geralmente encontram-se sem proteção, revela que este trecho de rodovia encontra-se fora dos padrões de segurança dispostos nos manuais internacionais de segurança viária e em desacordo com o conceito de entorno tolerante (rodovias que perdoam).

Conforme o levantamento dos custos relativos aos danos causados ao meio ambiente e aos motoristas que trafegam pela via, assim como a avaliação do risco da lateral da via, foi possível observar que medidas de engenharia têm efeitos mais rápidos que treinar motoristas para diminuir os acidentes ou suas consequências, assim, devido à gravidade do problema é indispensável que se tome providências imediatas para diminuição dos riscos de colisões com árvores. A alternativa que parece ter melhor custo-benefício é a remoção da vegetação existente na faixa livre de obstáculos inserida dentro da faixa de domínio, principalmente as árvores de grande porte próximas à pista em que não exista obstáculo físico (defensas ou taludes de corte) para evitar o impacto direto. Esta vegetação poderia ser substituída por espécies arbustivas que, além do benefício ambiental, auxiliariam a não tornar a paisagem monótona ao motorista, e em caso de saída de pista, poderiam servir como barreira para amortecimento de colisões. Destaca-se ainda, a possibilidade de conversão desta grande plantação existente em recursos financeiros, através da venda da madeira, que poderiam ser investidos na própria segurança viária (sinalização, colocação de defensas e programas educativos, por exemplo) ou mesmo incrementando a infraestrutura da fiscalização do órgão com circunscrição sobre a via (compra de viaturas e equipamentos para a Polícia Rodoviária Federal).

Uma alternativa no caso de espécies arbóreas em locais de difícil acesso, impossibilitando a sua supressão, seria a colocação de defensas ao longo da rodovia permitindo a manutenção da vegetação atual. Porém, esta alternativa, provavelmente não teria o mesmo custo benefício da remoção da vegetação já que, além do alto custo para a sua implantação e manutenção, não haveria a área livre 
Revista Nacional de

Gerenciamento de Cidades

para redução da velocidade em caso de acidentes do tipo saída de pista. Também, nos acidentes envolvendo veículos em altas velocidades poderá ocorrer a transposição destas barreiras e consequente colisão com as árvores, ou mesmo o retorno do veículo descontrolado para a via, podendo envolver outros veículos no acidente.

Além do risco de colisão de um veículo com a vegetação inserida na faixa de domínio, essa mesma árvore poderá cair sobre a pista (seja resultado do choque de veículo, chuva forte ou de doenças na vegetação, o queda de galhos) o que pode comprometer a segurança da via e a vida dos motoristas. Portanto, uma ferramenta simples para a diminuição da mortalidade dos acidentes de trânsito que envolvem a saída da pista de rolamento de veículos desgovernados, (uma vez que prevenção ainda é a melhor opção) é a remoção do exemplar arbóreo que estiver comprometendo a segurança dos motoristas. E nestes casos a supressão dessa vegetação deverá ser realizada sem a compensação ambiental, pois o bem ambiental é uma extensão do bem da vida, devendo o primeiro ser prioridade apenas quando servir para garantir o segundo. Dessa forma, a segurança dos motoristas deve ser mantida ainda que necessário à supressão de vegetação nativa para que isso ocorra.

Como já citado, o artigo 50 do Código de Trânsito Brasileiro (CTB), estabelece que o uso de faixas laterais de domínio e das áreas adjacentes às estradas e rodovias deverá obedecer às condições de segurança do trânsito estabelecidas pelo órgão ou entidade com circunscrição sobre a via. Tanto ao DNIT quanto ao DER compete essa fiscalização, bem como a defesa contra construções que infrinjam regulamentos administrativos e os preceitos legais contidos na legislação em vigor, podendo exigir que se as desfaça. Ambos os órgãos estabelecem normas que regulamentam a manutenção das vegetações nas laterais das rodovias, assim como o Regimento Interno do DER, Portaria SUP/DER-06511/06/1975, que remete ao DER as Atribuições de Órgãos e a Competência de Dirigentes, estabelecendo com uma das duas responsabilidades a manutenção das 
Revista Nacional de

Gerenciamento de Cidades

Faixas de Domínio das Rodovias, assim como "a REMOÇÃO de árvores e arbustos da faixa de domínio", também a Portaria $n^{\circ} 19$, de 10/01/1949 e $n^{\circ} 348$, de 17/04/1950 - Reeditado em 1973 do DNIT em seu artigo 24 determina que nas zonas rurais a faixa de domínio terá uma largura mínima limitada pela distância de 10 metros, contada a partir das cristas dos cortes ou dos pés dos aterros, para cada um dos lados, não sendo inferior aos valores estabelecidos pelo referido órgão, que variam de 30 a 80 metros. Em resumo, é possível observar que a lei federal remete a competência para regulamentar a vegetação no entorno das rodovias em razão à segurança dos motoristas aos referidos órgãos, que por sua vez possuem manuais com normas próprias que não citam a necessidade da compensação ambiental. Entre os órgãos que regulamentam as rodovias, é possível citar a Agência Reguladora de Transportes de São Paulo (ARTESP) que recomendou por uma questão de segurança que não fossem plantadas árvores à beira das estradas e, também regulamentou em Edital de Licitação que todas as Concessionárias eliminem em até 24 horas, árvores das Faixas de Domínio que representem perigo ao tráfego (ARTESP, 1997).

Diante do exposto, nota-se o conflito das leis citadas, pois enquanto exigem a compensação ambiental, também remetem a competência da manutenção dessa vegetação a determinados órgãos, que deixam claro que nas margens das rodovias não deve haver vegetação arbórea por uma questão de segurança. Portanto, considerando que a compensação ambiental torna todo o procedimento de remoção arbórea lento, burocrático e oneroso, a vegetação arbórea plantada nas faixas de domínio deixam os motoristas expostos aos riscos citados anteriormente, deve-se fazer o necessário para que a segurança dos motoristas seja objetivo primordial, retirando as árvores das zonas livres de obstáculos dentro das faixas de domínio sem a compensação ambiental e licenciamento ambiental.

Como então se deve proceder para gerir este conflito aparente destas normas legais; de um lado a norma legal de trânsito, o que inclui a segurança viária; de outro, a norma legal ambiental que, entre outras coisas, exige compensação em 
Revista Nacional de

Gerenciamento de Cidades

caso de supressão de árvores? Na lei brasileira para disciplinar tal conflito e para que volte a "harmonia" jurídica podem ser eleitos dois princípios que, embora muito usados na esfera penal, começam a ser introduzidos pelos tribunais em discussões civis: princípio da especialidade e princípio da consunção.

No primeiro princípio, a lei posterior (mais nova) poderia revogar (mesmo que tacitamente) a lei anterior. Surgiu, porém, numa interpretação jurisprudencial o princípio civil da especialidade, quando os tribunais decidiram interpretar o $\S 2^{\circ}$ do art. $2^{\circ}$ da LICC (lei de introdução ao código civil). Dessa forma, passaram os juízes a considerar que prevalecerá a lei especial sobre a geral, ainda que posteriormente editada a geral, caso não haja revogação expressa. No caso concreto, portanto, há um fator adicional. Tanto a lei que rege a segurança viária quanto a que disciplina o trato com o meio ambiente são leis especiais. Ora, se o princípio da especialidade afasta a norma geral, evidente que ele também afastará outra norma especial. No direito brasileiro, costuma-se dizer que aquilo que pode "o mais", também poderá "o menos". Portanto, a lei de trânsito, especial que é, afasta a incidência de lei ambiental sobre faixas de domínio. A área ocupada pela rodovia reger-se-á, exclusivamente, pela norma de trânsito, afastando-se a ambiental e opondo-se a ela. Logo, uma vez que a compensação é matéria ambiental e, considerando que a lei de trânsito possui jurisdição exclusiva sobre as faixas de domínio, conforme estabelecido pelo CTB, as eventuais árvores poderão ser simplesmente suprimidas, não havendo o quê se falar em compensação, com o objetivo único de preservação da vida humana.

No segundo princípio, o da consunção, muito utilizado também na esfera penal, onde o fato mais amplo ou de maior gravidade absorve o mais restrito e menos gravoso. Exemplo básico está no fato (mais grave) que é o homicídio, onde o fato menos gravoso, a lesão corporal para se atingir o homicídio, ficará perfeitamente absorvido. Da mesma forma, na esfera civil, o fato mais grave, a perda de inúmeras vidas humanas num acidente viário, absorve e retira o menos grave, a supressão de contáveis árvores (nativas ou não) das faixas de domínio. 
Revista Nacional de

Gerenciamento de Cidades

Pode-se, portanto, defender juridicamente que em qualquer faixa de domínio é matéria sujeita apenas à lei de trânsito. A lei ambiental fica afastada, absorvida e totalmente eliminada do contexto. Ora, se a lei ambiental desapareceu do fenômeno morte causado por árvore em faixa de domínio, claro que a tal compensação ambiental também terá desaparecido.

\section{CONSIDERAÇÕES FINAIS}

Este trabalho teve a intenção de trazer à tona a discussão sobre a supressão de árvores nativas na área livre de obstáculos localizado na lateral da rodovia e dentro da faixa de domínio. A argumentação jurídica é de que o bem da vida deve se sobrepor ao bem do meio ambiente. Dessa forma, o artigo apresentou as legislações existentes sobre a manutenção da rodovia e legislação ambiental. Alguns pontos destas legislações são contraditórios levando a um impasse jurídico. Se por um lado a legislação ambiental defende os aceiros para proteger as áreas de preservação ambiental, por outro impedem a remoção de árvores nativas na beira de rodovias sem compensação ambiental, que além de ceifar vidas humanas de uma forma cruel, pois seriam plenamente evitáveis, podem gerar um passivo ambiental superior ao dano da remoção destes exemplares nativos devido a incêndios e derramamento de produtos perigosos cujo dano pode ser intensificado se for atingido os elementos de drenagem da rodovia (podendo chegar aos rios ou ser infiltrado nos lençóis freáticos). Por outro, o CTB estabelece que o órgão responsável pela manutenção da via tem autonomia para tomar ações para a prevenção de acidentes. No entanto estes se veem refém da legislação ambiental que limita as suas ações neste sentido ao exigir a compensação ambiental e o licenciamento ambiental para supressão das árvores nativas. A simples remoção das árvores na lateral das rodovias seria uma medida simples e eficaz para a redução de mortes desnecessárias. Estamos na década de ação para o trânsito seguro lançado pela Organização das Nações Unidas, o momento ideal para trazer à tona esta discussão no país sendo urgente a revisão deste assunto. 


\section{AGRADECIMENTOS}

Agradecemos à FAPESP (Fundação de Amparo a Pesquisa do Estado de São Paulo) pelo apoio ao desenvolvimento do projeto.

\section{REFERÊNCIAS BIBLIOGRÁFICAS}

AASHTO. Highway Design and Operational Practices Related to Highway Safety. Washington, D. C.: American Association of State Highway and Transportation Officials, 1974.

AASHTO. Roadside Design Guide. Washington, D. C.: American Association of State Highway and Transportation Officials. Update, 2006.

AASHTO. Strategic highway safety plan: Percent of Fatal Crashes Involve Leaving the Roadway. Disponível em: <http://safety.transportation.org/guides.aspx?cid=27>. Acesso em: 20 de março de 2013.

ARTESP. Edital de Licitação n 016/CIC/97 - Centrovias. São Paulo, 1997.

ARTESP. Relatório Consolidado de Segurança Viária. Agência Reguladora de Serviços Públicos Delgados de Transportes do Estado de São Paulo. São Paulo, 2010.

BRASIL. Código de Trânsito Brasileiro - Lei no. 9.503 de 23 de setembro de 1997. Disponível em: < http://www6.senado.gov.br/mate-pdf/105275.pdf>. Acesso em: 18 de fevereiro de 2013.

BRASIL. Departamento Nacional de Estradas de Rodagem. Ministério dos Transportes. Normas para o projeto das estradas de rodagem. Rio de Janeiro, 1973.

BRASIL. Departamento Nacional de Infraestrutura de Transportes. Diretoria Geral. Diretoria Executiva. Instituto de Pesquisas Rodoviárias. Custos de acidentes de trânsito nas rodovias federais: sumário executivo (IPR. Publ., 733). Rio de Janeiro, 2004.

BRASIL. Departamento Nacional de Infraestrutura de Transportes. Diretoria de Planejamento e Pesquisa. Coordenação Geral de Estudos e Pesquisa. Instituto de Pesquisas Rodoviárias. Manual para ordenamento do uso do solo nas faixas de domínio e lindeiras das rodovias federais (IPR. Publ.,712). 2. ed. Rio de Janeiro, 2005.

BRASIL. Departamento Nacional de Infraestrutura de Transportes. Diretoria Executiva. Instituto de Pesquisas Rodoviárias. Manual de vegetação rodoviária (IPR. Publ., 734). Rio de Janeiro, 2009.

BRASIL. Departamento Nacional de Infraestrutura de Transportes. Ministério dos Transportes. Instruções de proteção ambiental das faixas de domínio e lindeiras das rodovias federais. Rio de Janeiro, 2005.

BRASIL. Resolução SMA $n^{\circ} 81$ de 01 de dezembro de 1998. Disponível em: <http://licenciamento.cetesb.sp.gov.br/legislacao/estadual/resolucoes/1998_Res_SMA_81.pdf>. Acesso em: 21 de março de 2013. 
Revista Nacional de

Gerenciamento de Cidades

BRASIL. Resolução SMA $n^{\circ} 18$ de 11 de abril de 2007. Disponível em: < http://www.itatiba.sp.gov.br/templates/midia/Licenciamento_Ambiental/Legislacao/resolucao\%20sma \%20n.\%2018-07\%20-\%20corte\%20de\%20arvores\%20isoladas.pdf>. Acesso em: 21 de março de 2013.

BRASIL. Código civil. 63. Ed. São Paulo: Saraiva, 2012.

BRASIL. Decreto Lei $N^{\circ} 2.661$, de 8 de julho de 1998. Disponível em: < http://www.planalto.gov.br/ccivil_03/decreto/d2661.htm>. Acesso em: 23 de janeiro de 2013.

DNIT. Faixa de domínio. Disponível em: <http://www.dnit.gov.br/rodovias/operacoesrodoviarias/faixa-de-dominio>. Acesso em: 14 de março de 2013.

FERRAZ, Antonio Clóvis Pinto et al. Segurança Viária. Suprema Gráfica e Editora. São Carlos, 2012.

FURTADO, Fernanda. Andrade Mattar. Direitos Humanos, ética ambiental e o conflito entre os direitos fundamentais. Revista Fundação Escola Superior do ministério público federal. Edição Especial. P.50-110. Brasília, 2003.

HADDON JR., Willian. The changing approach to the epidemiology, prevention, and amelioration of trauma: the transition to approaches etiologically rather than descriptively based. American Journal of

Public Health, 1968.

IBGE. IPCA - Índice de Preços ao Consumidor Amplo. Disponível em: $<$ http://www.ibge.gov.br/home/estatistica/indicadores/precos/inpc_ipca/defaultinpc.shtm>. Acesso em: 18 de dezembro de 2012.

IPEA. Impactos sociais e econômicos dos acidentes de trânsito nas aglomerações urbanas. Brasília, 2003.

IPEA. Impactos sociais e econômicos dos acidentes de trânsito nas rodovias brasileiras. Brasília, 2006.

MACEDO, Edivaldo Lins. Noções de Topografia Para Projetos Rodoviários. Disponível em < http://www.topografiageral.com/Curso/capitulo\%2005.php>. Acesso em: 04 de março de 2013.

MARAFON, M. A.; VAREJÃO, L. C. S. Gestão da Faixa de Domínio do DNIT. In: Encontro nacional de conservação rodoviária, Belo Horizonte. Anais da 14ª ENACOR. Belo Horizonte/MG, 2009.

OPAS/OMS. Conferencia pan-americana sobre segurança no trânsito. Disponível em: <http://transcidades.com.br/pesquisa\%20observatorio.pdf>. Acesso em: 21 de março de 2013. Brasília, 2005.

SHA (STATE HIGHWAY ADMINISTRATION). Guidelines for Traffic Barrier Placement and End Treatment Design. Maryland Department of Transportation. March, 2006. Disponível em: http://www.marylandroads.com/businessWithSHA/bizStdsSpecs/desManualStdPub/publicationonline/ ohd/bookstd/index.asp. (Acessado em 17/05/13).

TRINDADE, Antonio Augusto Cançado. Direitos Humanos, desenvolvimento sustentável e meio ambiente. Instituto Interamericano de direitos humanos. Brasília, 1992.

WHO. World Report on Road Traffic Injury Prevention. Geneva, 2004. 